\title{
Onde fica São Paulo? No coração e na devoração de Macunaíma
}

\section{Wilson Ponciano Junior ${ }^{*}$}

Resumo: Este ensaio apresenta um estudo da relação entre a representação da cidade de São Paulo e os elementos femininos na rapsódia Macunaíma, o herói sem nenhum caráter, de Mário de Andrade.

\begin{abstract}
This essay presents a study of the relationship between the representation of São Paulo City and the feminine elements in the rapsode Macunaíma, o herói sem nenhum caráter (1928), by Mário de Andrade.
\end{abstract}

Keywords: Macunaíma; Mário de Andrade; city; feminine.
Palavras-chave: Macunaíma; Mário de Andrade; cidade; feminino.

Quando Rachel Glezer (1994) afirma que "trabalhar com o urbano é sempre e também trabalhar com emoções, percepções, sentidos e visualizações" (p. 165), não há como deixar de pensar numa aproximação com o que se entende por trabalhar com literatura. No ensaio "Visões de São Paulo", a historiadora relata e problematiza o processo de modernização pelo qual essa cidade passou no início do século XX. E deixa clara a importância de se preservar uma espécie de "memória coletiva".

Sem as descrições dos homens do passado, sem os traços do que construíram, cada um de nós, ao enfrentar o estudo da cidade em seu desenvolvimento histórico, sente-se obrigado a "reconstruir" o passado para tentar entender o que os seres humanos que aqui habitaram, construíram, pensaram, sonharam e realizaram. (GLEZER, 1994, p. 175)

Novamente, é impossível ignorar que também parte das pesquisas em literatura se ocupa em "reconstruir" trajetórias de obras e autores, resgatando e identificando as origens das marcas indeléveis que deixam em seus leitores. O fenômeno da consagração e permanência de alguns textos se explica pelo modo como certos autores na concepção de suas obras literárias agem como "as cidades [que] desenvolvem suntuosamente uma linguagem mediante duas redes diferentes e superpostas: a física, que o visitante comum percorre até perder-se na sua multiplicidade e fragmentação, e a simbólica, que a ordena e interpreta."

\footnotetext{
* Mestrando do Programa de Pós-Graduação em Letras da UFRGS.
} 
(ANGEL, 1985, p. 53). Esse é o caso do texto aqui estudado, às vésperas dos oitentas anos de sua publicação.

Macunaíma, nascido numa tribo de índios-pretos no fundo do mato-virgem, migra para São Paulo atrás da muiraquitã, presente de Ci, a Mãe do Mato. Após várias peripécias na cidade grande, resgata a pedra ao derrotar o gigante Piaimã e regressa à terra-natal, onde, por não conseguir se readaptar, acaba morrendo. Qualquer síntese da rapsódia de Mário de Andrade não evidenciaria a riqueza dos elementos mágicos da tradição (resgatados em pesquisas pelo autor, e, em grande parte, motivo de consagração do texto), mas deixaria clara a proposta do autor em cotejar as diferentes culturas: a do primitivo e a do civilizado.

Nesse prisma, a metrópole citada surge não apenas como palco das aventuras do "herói sem nenhum caráter", mas como um dos principais desafios a serem vencidos por ele. E a obra marioandradiana se impõe como um desafio ao leitor, entre outros aspectos pela construção. Assim, não é apenas a São Paulo ficcional de Macunaíma, o herói sem nenhum caráter que se assemelha à descrição do antropólogo François Laplantine (1993), mas a própria narrativa.

Uma cidade de tal forma múltipla, contraditória, desconcertante não se deixa apreender a partir da lógica que organiza nossas velhas cidades européias. Daí o sentimento de liberdade que experimentamos em São Paulo: ela nos liberta de um modelo no singular, que nos surge então como uma prisão, como as análises categóricas e classificatórias de que somos tão ávidos do outro lado do Atlântico.

Os europeus, sobretudo os franceses, para pensar, têm necessidade de distinguir e opor: o branco e o negro, a tradição e a modernidade, a civilização e a barbárie, o sagrado e o profano. Ora, eis que em São Paulo, mais que em qualquer outro lugar do Brasil, as coisas que percebemos como contrárias coexistem entre si, o que aprendemos a separar junta-se, o que consideramos contraditório casa-se. São Paulo é uma mistura complexa de doçura e violência, de vida pública e privada, de razão e afetividade, de individualismo e espírito de clã. (LAPLANTINE, 1993, p. 29)

Nos ensaios de Um olhar francês sobre São Paulo, em parceria com o psiquiatra Claude Olievenstein, Laplantine delineia interessante painel da maior capital brasileira, num misto de impressão afetuosa e observação criteriosa. Ao desvelar contrastes e contradições na sociedade paulistana, o estudioso, por extensão, compõe um retrato de todo o país. Não por outro motivo, Macunaíma, entidade cuja trajetória, desde a gênese, impregna o imaginário desde povo, é a síntese da polimorfa identidade nacional.

Nas primeiras cenas da narrativa, dedicadas ao nascimento e aos primeiros anos do filho da índia tapanhumas, já aparecem indícios de que alguns valores de homem branco, por assim dizer, civilizado, teriam sido legitimados dentro da tribo. Lê-se sobre o herói, por exemplo, no primeiro capítulo, que "vivia deitado mas si punha os olhos em dinheiro, Macunaíma dandava pra ganhar vintém.” (ANDRADE, s.d., p. 7). A denúncia com sabor de 
glosa sobre o indígena cooptado pela noção de dinheiro ressurge nas palavras de Macunaíma para seu herdeiro com Ci: “- Meu filho, cresce depressa pra você ir pra São Paulo ganhar muito dinheiro.”. (ANDRADE, s.d., p. 25). A capital paulista é inscrita, pois, já na primeira menção, como a terra das oportunidades, especialmente de enriquecimento financeiro.

As palavras de Macunaíma não fariam sentido sem prévio contato com um citadino, uma vez que, na cultura indígena, as relações de troca desconheciam/desconhecem a noção de dinheiro. ${ }^{1}$ De forma sutil, Mário de Andrade introduz a idéia de que mesmo aquela tribo lendária já teria sofrido influência do processo de colonização empreendido pelo "homem branco" (europeu). Mas o autor confere tom mítico ao início da narrativa. O choque entre culturas, seria anterior ao nascimento do herói. Os indígenas já trariam arraigado o valor da nova moeda - dinheiro. O implícito, o ambíguo e o indeterminado imperam na obra a fim de legitimar a personagem-título, assim características da personagem também são características do texto de onde ela emerge e promovem ainda mais a aproximação de Macunaíma e São Paulo.

A ambigüidade da personagem Macunaíma também é a ambigüidade de São Paulo, de sua história e seu rosto. (...) São Paulo como centro industrial, econômico, de imigração, de tendências políticas, de misturas sociais, raciais e religiosas, de refinamento e pobreza, com crescimento sempre desordenado e espontâneo, aceitando a máquina indiscriminadamente, com todos os seus benefícios e enganos, é por definição uma cidade modernista. (JAFFE, 2001, p. 52)

Assim como se valeu da indeterminação do tempo nas aventuras de Macunaíma, própria do mito, Mário de Andrade optou por ignorar as noções de distância e espaço, valendo-se das diversas regiões do Brasil (e da América do Sul como um todo) para narrar as aventuras do "herói de nossa gente" (ANDRADE, s.d, p. 7), segundo o próprio autor um homem "desgeograficado". Não por outro motivo, explica-se a origem dos presentes recebidos pelo filho de Ci e Macunaíma, inclusive de São Paulo:

Todos agora só matutavam no pecurrucho. Mandaram buscar pra ele em São Paulo os famosos sapatinhos de lã tricotados por dona Ana Francisca de Almeida Leite Morais e em Pernambuco as rendas das Rosa dos Alpes, Flor de Guabiroba e Por Ti Padeço tecidas pelas mãos de dona Joaquina Leitão mais conhecida pelo nome de Quinquina Cacunda. Filtravam o milhor tamarindo das irmãs Louro Vieira, de Óbidos, pro menino engolir no refresco o remedinho pra lombriga. Vida feliz, era bom!.... (ANDRADE, s.d, p. 25)

Devido à morte prematura do filho, o casamento de Ci e Macunaíma se desfaz. A rainha das icamiabas despede-se do marido, entregando-lhe uma muiraquitã e subindo por um cipó para o céu, onde se torna a estrela Beta de Centauro. O herói passa a usar a pedra mágica

\footnotetext{
${ }^{1}$ No ensaio "Macunaíma pra lá de Brasil", Telê Porto Ancona Lopez analisa outras implicações interessantes sobre a segunda cena, vendo no gesto de Macunaíma achatando a cabeça do filho uma referência aos nordestinos que migram para o sul (São Paulo) atrás de oportunidades de emprego. O mesmo já fizera M. Cavalcanti Proença em seu conhecido estudo, apontando que seria essa a intenção de Mário de Andrade ao construir o episódio.
} 
como um tembetá, colocando-o no queixo furado. Porém, em luta contra a boiúna Capei (cobra-grande), ele perde o amuleto. Apiedado com o sofrimento dele, o Negrinho do Pastoreio manda para ajudar o herói o passarinho uirapuru, que conta que

(...) Macunaíma havia de ser marupiara não, porque uma tracajá engolira a muiraquitã e o mariscador que apanhara a tartaruga tinha vendido a pedra verde pra um regatão peruano se chamando Venceslau Pietro Pietra. O dono do talismã enriquecera e parava fazendeiro e baludo lá em São Paulo, a cidade macota lambida pelo igarapé Tietê. (ANDRADE, s.d., p. 34).

Ciente da localização da pedra, o herói decide resgatá-la. Junto com os irmãos, começa a jornada para São Paulo. Deixa, entretanto, sua consciência na ilha de Marapatá. Reúne também uma divisas para a viagem. Nesse trecho, vê-se novamente o cotejo de valores do primitivo e do civilizado. É importante que se diga, porém, que diferentemente da perspectiva anterior aqui se acrescentam dois novos itens: a perspectiva indígena e a importância do trabalho para a manutenção dos recursos financeiros. ${ }^{2}$

\begin{abstract}
Macunaíma vinha com os dois manos pra São Paulo. Foi o Araguaia que facilitou-lhes a viagem. Por tantas conquistas e tantos feitos passados o herói não ajuntara um vintém só mas os tesouros herdados da icamiaba estrela estavam escondidos nas grunhas do Roraima lá. Desses tesouros Macunaíma apartou pra viagem nada menos de quarenta vezes quarenta milhões de bagos de cacau, a moeda tradicional. (...) Porém entrando nas terras do igarapé Tietê adonde o burbom vogava e a moeda tradicional não era mais cacau, em vez, chamava arame contos cotecos milréis borós tostão duzentorréis quinhentorréis, cinqüenta paus, noventa bagarotes, e pelgas cobres, xenxéns caraminguás selos bicos-de-coruja maçuni bolada calcário gimbra siridó bicha e pataracos, assim, adonde até liga pra meia ninguém comprava nem por vinte mil cacaus. Macunaíma ficou muito contrariado. Ter de trabucar, ele, herói... Murmurou desolado:

- Ai! que preguiça!... (...)

Quando chegaram em São Paulo, ensacou um pouco do tesouro pra comerem e barganhando o resto na Bolsa apurou perto de oitenta contos de réis. Maanape era feiticeiro. Oitenta contos não valia muito mas o herói refletiu bem e falou pros manos:

- Paciência. A gente se arruma com isso mesmo, quem quer cavalo sem tacha anda de a-pé...

Com esses cobres é que Macunaíma viveu. (ANDRADE, s.d., p. 37-40)
\end{abstract}

Quando o valor do cacau não o ajuda como ele imaginava, mesmo sem a proteção da muiraquitã, o herói se beneficia de mágica para a "navegação social" em São Paulo. Uma poça encantada por Santo Tomé o deixa branco. Os outros dois irmãos também se banham na água, mas Jiguê fica apenas vermelho e Maanape permanece negro. Através do trio, gerados por uma mesma mãe, Mário faz referência direta às raças que originaram o povo brasileiro, e denuncia, indiretamente, pelo que segue, o preconceito na cidade grande, apontando a diferenciação no tratamento recebido pelos três, devido às diferentes cores de peles. Isso porque o convívio dos diversos povos na cidade, bem como as relações entre os gêneros masculino e feminino, sempre despertou interesse no autor.

\footnotetext{
${ }^{2}$ Cf. Proença: “(..) esse espírito de aventura do brasileiro, contrapondo-se ao trabalho, não é invenção de Mário de Andrade mas observação de sociólogos eruditos falando sério, mestres como Sérgio Buarque de Hollanda.” (p. 12)
} 
Na série de crônicas para a revista Ilustração Brasileira, escrita nos primeiros anos da década de 1920, por exemplo, percebe-se como o polígrafo mantinha relação de "amante incorrígivel" com sua terra-natal, exaltando-lhe as boas qualidades, sem ignorar as más, a ponto de afirmar, na primeira destas crônicas, que São Paulo "é agressiva e misteriosa como os seus heróis; suas belezas recônditas; raro o estrangeiro que alcança levantar um pouco o pesado manto de segredo em que se embuça." (ANDRADE, 2004, p. 73) ${ }^{3}$.

O mistério da noite e das mulheres e a agressividade das máquinas são usados na narrativa para reproduzir a aura da urbe e a posição do estrangeiro descritas anos antes na crônica e propor uma discussão sobre a natureza do homem primitivo ser ou não diferente da do homem civilizado.

E foi numa boca-da-noite fria que os manos toparam com a cidade macota de São Paulo esparramada a beira-rio do igarapé Tietê. (...) Todas as estrelas tinham descido do céu branco de tão molhado de garoa e banzavam pela cidade. Macunaíma lembrou de procurar Ci. (...) Macunaíma campeou, campeou mas as estradas e terreiros estavam apinhados de cunhas tão brancas tão alvinhas, tão!... Macunaíma gemia. Roçava nas cunhas murmurejando com doçura: "Mani! Mani! filhinhas da mandioca..." perdido de gosto e tanta formosura. Afinal escolheu três. Brincou com elas na rede estranha plantada no chão, numa maloca mais alta que a Paranaguara. Depois por causa daquela rede ser dura, dormiu de atravessado sobre os corpos das cunhas. E a noite custou pra ele quatrocentos bagarotes. (ANDRADE, s.d., p. 41)

Quando se fala da sexualidade exacerbada do Macunaíma de Mário de Andrade, há uma grande tendência em priorizar as descrições pormenorizadas de sexo dos primeiros capítulos, ignorando as das relações que o herói mantém durante e depois de sua permanência na cidade. Contudo, o comportamento luxurioso da personagem-título com as cunhadas e a rainha das icamiabas só deveria ser entendido se comparado ao dele perante as mulheres da cidade, porque, como se vê, a narrativa dobra inúmeras vezes sobre si mesma, valorizando as comparações entre primitivo e civilizado.

No início da rapsódia, ao "brincar" com Sofará e Iriqui, o herói demonstra estar alheio ao conceito de fidelidade. Estar com as cunhadas é para o menino Macunaíma apenas uma grande diversão num espírito de "comunismo sexual" (LAPLANTINE, 1993, p. 43). Até pela pouca idade, a traição e a libertinagem não podem ser entendidas como a postura de um homem primitivo, uma vez que, nas mesmas circunstâncias, o comportamento de Jiguê é diametralmente oposto. Na "força do homem” (ANDRADE, s.d., p. 7), Jiguê não só é fiel nos relacionamentos com as esposas, mas também no relacionamento com os irmãos. O mesmo se aplica a Maanape, “já velhinho” (ANDRADE, s.d., p. 7). A fidelidade aos irmãos, talvez, seja a característica mais latente nesta personagem, que não chega a se envolver com mulheres na

\footnotetext{
${ }^{3}$ Nesta crônica, datada de novembro de 1920, o autor revela os preparativos da cidade de São Paulo para as comemorações do centenário da Independência do Brasil.
} 
história. A exemplo do que fez sobre as raças, Mário de Andrade, provavelmente, buscou estabelecer as facetas do ser masculino através dos estágios de vida dos três irmãos.

Mesmo que desenvolva corpo de homem adulto por encantamento, as atitudes de Macunaíma quanto a sexo são ímpares e não-lineares. A personagem passa por um processo de amadurecimento durante a narrativa, principalmente quando chega à cidade. Antes ainda, quando se une a $\mathrm{Ci}$, ele já dá sinais de uma mudança. Adota comportamento semelhante à de Jiguê enquanto vive com ela um tórrido, contudo rápido relacionamento. Ele se torna imperador do mato-virgem e pai. Não deixa de ser preguiçoso, mas essas duas mudanças lhe dão auto-confiança para as intempéries seguintes. Abandonado pela icamiaba após a morte do bebê, Macunaíma se torna nostálgico, melancólico. Mas empreende a viagem para São Paulo.

A busca da muiraquitã, que impulsiona a narrativa, em última instância é a tentativa do herói de resgatar Ci. Apesar de manter relações com as "filhas de Mani”, logo na primeira noite em São Paulo, o herói nunca perde de vista seu amor pela mãe do mato-virgem, a ponto de ficar com "os dedos agora cobertos de berrugas de tanto apontarem para Ci estrela." (ANDRADE, s.d., p. 37). Ele "brinca" com as "cunhãs" da cidade sem compromisso, como "brincava" com as da tribo. 4

Na cidade, contudo, Macunaíma tem que lidar com uma nova situação: pagar para "brincar". O mercado sexual parece não incomodá-lo a princípio, mas sugere uma questão paradoxal na narrativa. Anteriormente, além de prazer para os desejos carnais, o herói buscava no sexo uma forma de dominação. No relacionamento com $\mathrm{Ci}$, por exemplo, fazer sexo era uma forma de exercer poder sobre ela.

Mesmo que sirva para reforçar a idéia de que para ele, apartado da amada, há uma distinção entre sexo e amor, o pagamento das prostitutas paulistanas sugere a fácil cooptação do herói ao sistema. Porém, se totalmente cooptado o herói jamais tentaria, como na primeira manhã em São Paulo, dominar a Máquina.

A inteligência do herói estava muito perturbada. Acordou com os berros da bicharia lá embaixo nas ruas, disparando entre as malocas temíveis. (...) De -manhãzinha [as cunhãs] ensinaram que todos aqueles piados berros cuquiadas sopros roncos esturros não eram nada disso não, eram mas cláxons campainhas apitos buzinas e tudo era máquina. (...) Eram máquinas e tudo na cidade era só máquina! O herói aprendendo calado. De vez em quando estremecia. Voltava a ficar imóvel escutando assuntando maquinando numa cisma assombrada. Tomou-o um respeito cheio de inveja por essa deusa de veras forçuda, Tupã famanado que os filhos da mandioca chamavam de Máquina, mais cantadeira que a Mãe-d'água, em bulhas de sarapantar. Então resolveu ir brincar com a Máquina pra ser também imperador dos filhos da mandioca. (ANDRADE, s.d., p. 41)

\footnotetext{
${ }^{4}$ Macunaíma envolve-se também com a esposa de Jiguê na cidade, a piolhenta Suzi. Mantém com ela relacionamento semelhante ao vivido com Sofará e Iriqui. Percebe-se não só o interessante do herói pelas três, mas o caráter dissimulado de todas nas estratégias utilizadas para camuflar o adultério.
} 
Mesmo que se adapte rapidamente a situação e formule uma idéia a respeito da dominação dos homens pela Máquina ou pelas mulheres, ao longo da narrativa, a “inteligência do herói” fica cada vez mais perturbada. Macunaíma estabelece relações semelhantes com as "cunhãs" e com a Máquina. Ele nunca chega a reconhecer sua função na cidade, fica eternamente dividido entre cooptado ou cooptador. Ao mesmo tempo em que cede aos apelos das mulheres e da Máquina, tenta volta à posição de Imperador, principalmente sobre seus irmãos. ${ }^{5}$

Macunaíma passou então uma semana sem comer nem brincar só maquinando nas brigas sem vitória dos filhos da mandioca com a Máquina. A Máquina era que matava os homens porém os homens é que mandavam na Máquina.... (...) Até que uma noite, suspenso no terraço dum arranhacéu com os manos, Macunaíma concluiu:

- Os filhos da mandioca não ganham da máquina nem ela ganha deles nesta luta. Há empate.

Não concluiu mais nada porque inda não estava acostumado com discursos porém palpitava pra ele muito embrulhadamente muito! que a máquina devia de ser um deus de que os homens não eram verdadeiramente donos só porque não tinham feito dela uma Iara explicável mas apenas uma realidade do mundo. De toda essa embrulhada o pensamento dele sacou bem clarinha uma luz: Os homens é que eram máquinas e as máquinas é que eram homens. Macunaíma deu uma grande gargalhada. Percebeu que estava livre outra vez e teve uma satisfa mãe. Virou Jiguê na máquina telefone, ligou pros cabarés encomendando lagosta e francesas. (ANDRADE, s.d., p. 42-43)

No tangente às relações de poder, até mesmo numa perspectiva histórica é pertinente o cotejo dos comportamentos da personagem e da sociedade paulistana, como observada por Laplantine (1993):

São Paulo situada há anos-luz das civilizações indígenas e decididamente de costas para o velho Brasil patriarcal e paternalista do Nordeste? Não. Por um lado, as raízes ameríndias, escondidas sob a terra, enterradas sob o concreto, reaparecem e são um componente não confessado do comportamento cotidiano. Por outro, a sociedade paulistana apresenta uma face "tropical", que nada tem de verdadeiramente democrática e nem mesmo de liberal. É uma sociedade autoritária, que reproduz as relações de dependência e de tutela herdadas da colonização, na qual as classes dominantes não reconhecem direitos, mas concedem favores. (LAPLANTINE, 1993, p. 18).

Além dos fiéis irmãos, as analfabetas icamiabas também são surpreendidas e atingidas pelo herói em crise. "Premido pela necessidade financeira, querendo desfrutar os prazeres com as mulheres, escreve a suas 'mui queridas súbditas', as índias icamiabas, na qualidade de “imperador'”. (FONSECA, 1988, p. 279). Diferentemente da desesperança, da desilusão que se poderia imaginar ao desfazer a imagem de São Paulo como a "terra de oportunidade de enriquecimento", Macunaíma, consciente do esgotamento de suas divisas, revela novo delírio utópico - a noção de pertencimento àquele lugar.

O que vos interessará mias, por sem dúvida, é saberdes que os guerreiros de cá não buscam mavórticas damas para o enlace epitalâmico; mas antes as preferem dóceis e facilmente

\footnotetext{
${ }^{5} \mathrm{O}$ que se passa na obra de Mário de Andrade é fenômeno semelhante ao encontrado por Marshall Berman na poesia do autor francês: "Baudelaire nos mostra algo que nenhum escritor pôde ver com tanta clareza: como a modernização da cidade simultaneamente inspira e força a modernização da alma dos seus cidadãos.” (BERMAN, 1986, p.142)
} 
trocáveis por pequeninas e voláteis folhas de papel a que o vulgo chamará dinheiro - o "curriculum vitae" da Civilização, a que hoje fazemos ponto de honra pertencermos. (ANDRADE., s.d., p. 78)

Segundo o próprio Mário de Andrade, o nono capítulo da rapsódia, onde se percebem e se intensificam as mudanças sofridas pelo protagonista na cidade, constituiria o intermezzo da narrativa. Ao escrever a carta, Macunaíma evidencia na própria linguagem os problemas de adaptação que vivencia. ${ }^{6}$ Em estudo específico sobre "Carta pras Icamiabas", Maria Augusta Fonseca afirma que:

Pedante, pretensioso, citando os clássicos, Macunaíma dá vazão a sua cultura semi-letrada, e acoberta com a linguagem livresca e as alusões eróticas o principal objetivo da carta (conseguir dinheiro), crivando de subentendidos todo o discurso. (...) Na Carta, o herói prende-a um modo tradicional de narrar. Mas constrói um texto inteiramente descaracterizado por força do não comprometimento cultural, variando o tema na superfície. Sem poder assimilar o aprendido dentro de um novo padrão, sua carta passa a estampar uma sucessão não digerida de frases, trechos de poesia, discursos verborrágicos, citações em língua estrangeira, denominações em latim, citações de autores e obras, desentranhados do aprendizado "de orelha". (FONSECA, 1988, p. 279-281).

É importante notar, todavia, que os dois capítulos posteriores à "Carta pras Icamiabas" também mencionam o processo de incorporação da nova língua por Macunaíma. Em "PauíPódole" e "A velha Ceiuci", o herói não só aprende termos novos, como ensina alguns nomes feios, chega a discursar em praça pública com sucesso, mas acaba se metendo em confusão com estudantes logo em seguida.

O próprio clima da cidade grande também faz os três irmãos penarem, pelos motivos abaixo descritos - mesmo que Laplantine (1993) comente sobre uma realidade décadas posterior:

Nesse espaço desordenado e em contínua transformação, a temperatura não é mais clemente que o resto. São Paulo frequientemente permanece dias inteiros imersa em nevoeiro, e os termômetros eletrônicos nas principais avenidas podem muito bem indicar 17 graus centígrados num dia e 38 no dia seguinte. (LAPLANTINE, 1993, p. 8)

Em Roteiro de Macunaíma, M. Cavalcanti Proença elenca dezesseis passagens na rapsódia sobre doenças adquiridas pelo herói decorrentes da permanência em São Paulo, muitas delas venéreas. As doenças, mais a preguiça do herói, atrasam o embate com o Gigante/Venceslau.

\footnotetext{
${ }^{6}$ Antes da emblemática Semana de Arte Moderna, na segunda crônica da série "De São Paulo", criando a imagem de uma mulher para descrever a cidade, Mário de Andrade já atentava para as nuances da linguagem e do ritmo de vida dos paulistanos a partir do projeto de civilização, calcado na idéia de futurismo, dizendo que: "A cidade palpita num esto incessante de progresso e civilização. Nela formiga um povo multifário, internacional. Tudo são contrastes, neologismos. Os habitantes movem-se ágeis, a língua é mole, saboreada. Audácias e pasmaceiras...” (ANDRADE, 2004, p. 81)
} 
Depois um lapso de tempo nas atividades paralelas, Macunaíma retoma sua empreitada. Quando, enfim, vence o inimigo, os irmãos decidem retornar ao Uraricoera. Ao se despedir da cidade, o herói entristece, mas sente-se vitorioso.

Quando atravessaram o pico do Jaraguá Macunaíma virou pra trás contemplando a cidade macota de São Paulo. Maginou sorumbático muito tempo e no fim sacudiu a cabeça murmurando:

- Poucas saúde e muita saúva, os males do Brasil são...

Enxugou a lágrima, consertou o beicinho tremendo. Então fez um caborje: sacudiu os braços no ar e virou a taba gigante num bicho preguiça todinho de pedra. Partiram.

Depois de muito refletir, Macunaíma gastara o arame derradeiro comprando o que mais o entusiasmara na civilização paulista. Estavam ali com ele o revólver Smith-Wesson o relógio Pathek e o casal de galinha Legorne. Do revólver e do relógio Macunaíma fizera os brincos das orelhas e trazia na mão uma gaiola com o galo e a galinha. Não possuía mais nem um tostão do que ganhara no bicho porém lhe balangando no beiço furado pendia a muiraquitã. (ANDRADE, s.d., p. 147)

O revólver, o relógio e as galinhas são como troféus que Macunaíma leva consigo, como se tivesse dominado a cidade de fato. Entende-se essa atitude menos como a consciente vitória ou a completa alienação quanto ao uso de tais objetos e mais como um ato orgulhoso do herói para diminuir o sofrimento passado por ele e os irmãos em São Paulo, convertida no bicho-preguiça. Em última instância, a postura de Macunaíma assemelha-se ao fenômeno descrito por Marshall Berman (1985) ao analisar O Projeto Nevski, de Gogol:

Repetidas vezes, na literatura, na cultura popular, em nossa conversa cotidiana, encontraremos vozes como essa: quanto mais o falante condena a cidade, mais vividamente a evoca, mais atraente ela se lhe torna; quanto mais ele se afasta dela, mais profundamente se identifica com ela, mais claramente mostra que não pode viver sem ela. (BERMAN, 1985, p. 192)

Nem todas as metamorfoses e ressurreições de Macunaíma, contudo, são capazes de reverter sua incapacidade de se tornar citadino. Mesmo após a morte do Gigante e a nova posse do amuleto, o herói não consegue se recuperar dos males provocados pela cidade.

A indecidibilidade sobre o final do romance - ele significa uma vitória ou derrota do herói e do brasileiro ? - é também um ganho de nosso modernismo. A dúvida, nesse caso, é uma atitude ainda mais crítica do que uma posição taxativa. Mais do que posicionar-se, a conclusão indefinida exige reflexão, na direção do que mais tarde viria a chamar-se "obra aberta. (...) Se o texto fosse declaramente antropófago, essa dúvida certamente não existiria. A conclusão seria vitoriosa: o brasileiro engole o estrangeiro e o transforma, coloniza-o driblando-o. Com Macunaíma não é assim. (JAFFE, 2001, p. 53-54)

Além disso, perde os irmãos e, na seqüência, novamente a ligação com $\mathrm{Ci}$ - a muiraquitã. Trai a confiança de Vei, a sol, e é punido. Fica sozinho e vê-se numa encruzilhada, frente a possível definição de um novo caráter.

A volta tão sonhada ao Uraricoera-Paraíso é uma sucessão de decepções. Ao vir para o domínio da máquina, para o mundo capitalista, o protagonista abrira mão de sua consciência aquela que possuía, corroída pela alienação que os três primeiros capítulos já acusam. (...) E Macunaíma, ao final de seu périplo, tendo lutado, tendo perdido seu caminho de filho da luz e do calor, por duas vezes morrido e ressuscitado, já destroçado do Uraricoera pela vingança de Vei, sem talismã e toaliquiçus, vislumbra a própria alienação. Essa que o desgosta e aniquila. (...) Como todas as personagens que o acompanham ao longo da rapsódia - com exceção do 
gigante Piaimã -, não morre, transforma-se em estrela. Para continuar vivendo na terra, teria que chegar a uma definição. (...) $\mathrm{O}$ herói sem nenhum caráter prefere a seara do mito, a definição poética. Fica sugerida, ao lado da ambivalência de seus defeitos/qualidades, a validade de um outro tipo de caráter. Macunaíma se recusa a ser pedra, escolhe ir para o céu, virar, "pai-de-vivo" estrela. Transformado na Ursa Maior, é estrela-guia, é a constelação que paira sobre a Amazônia, terra sem fronteiras do deus Macunaíma. (LOPEZ, p. 198)

No "Epílogo", frente ao ninho desfeito, só resta ao herói seguir o exemplo das demais personagens. A ambição por poder e dinheiro e os arroubos por sexo não lhe correspondem mais. Pode, enfim, figurar ao lado de Ci. No céu, entretanto, “o imperador do Mato" continua em posição de destaque e adquire o status de deus. Anterior à escolha entre pedra e estrela, no entanto, situa-se outra feita por Macunaíma, ainda no campo simbólico, que explicaria o porquê do herói não ter abreviado seu sofrimento e "subido pelo cipó" antes:

Segundo a psicanálise contemporânea, a cidade é um dos símbolos da mãe, com o seu duplo aspecto de proteção e de limite. Em geral tem relação com o princípio de feminino. Da mesma forma que a cidade possui os seus habitantes, a mulher encerra nela os seus filhos. (CHEVALIER, 2005, p. 239)

A força de eventos ligados a duas figuras femininas motiva o herói e impulsiona toda a narrativa. Primeiro, a triste morte da mãe, somada à falta de recursos na tribo, faz com que ele e seus dois manos, Jiguê e Maanape, deixem a Uraricoera atrás de melhor destino. Segundo, quando a rainha das icamiabas/amazonas entrega a muiraquitã, objeto feito por elas do limo das águas, símbolo da fecundidade, para Macunaíma, este tem a chance de se reparar a perda da mãe provocada por ele mesmo. Em São Paulo, o resgate da muiraquitã converte-se na tentativa do herói em restabelecer os elos com o feminino, rompidos por sucessivas perdas.

A cidade, porém, não se revela maternal como desejava o coração do herói. Antes bmostra sua faceta de mulher fatal, devora; assim descrita, na segunda crônica "De São Paulo", por Mário: "Paulicéia é como brasileirinha nascida nessa idade-média em que uma parte de Minas adormeceu: alonga os babados da sai escura para fechar no segredo a volta sensual do tornozelo, mas traz nos lábios a rosa provocante das espanholas." (ANDRADE, 2004, p. 82). O herói não consegue dominar a cidade. A cidade, no entanto, também não consegue devorar o herói, porque ele ainda guardava no coração o amor pela mãe e por Ci. A cidade deixa-o combalido, mas ele resiste como mito e brilha no céu sobre ela.

\section{Referências}

ANDRADE, Mário de. Macunaíma, o herói sem nenhum caráter. São Paulo: Círculo do Livro, s.d. Coleção Grandes da Literatura Brasileira. 
De São Paulo: cinco crônicas de Mário de Andrade. Org., introd. e notas de Telê Ancona Lopez . São Paulo: Editora Senac São Paulo, 2004.

BERMAN, Marshall. Tudo que é sólido se desmancha no ar. A aventura da modernidade. Tradução de Carlos Felipe Moisés e Ana Maria L. Ioriatti. São Paulo: Companhia das letras, 1986.

CHEVALIER, Jean. Dicionário de símbolos: (mitos, sonhos, costumes, gestos, formas, figuras, cores, números). Jean Chevalier, Alain Gheerbrant, com a colaboração de: André Barbault... [et al.]; coordenação Carlos Sussekind; tradução Vera da Costa e Silva... [et al.]. - 19 . ed. Rio de Janeiro: José Olympio, 2005.

FONSECA, Maria Augusta. A carta pras Icamiabas. In: ANDRADE, Mário de. Macunaíma, $o$ herói sem nenhum caráter. Ed. crítica. Coord. Telê Porto Ancona Lopez. Paris: Association Archives de la Littérature latino-américaine, des Caraïbes et africaine du XX siécle; Brasília, DF: CNPq, 1988. (Coleção arquivos: v. 6).

GLEZER, Raquel. Visões de São Paulo. In: BRESCIANI, Stella (org). Imagens da cidade: séculos XIX e XX. São Paulo: Marco Zero. p. 163-175.

JAFFE, Noemi. Macunaíma. São Paulo: Publifolha, 2001.

LOPEZ, Telê Ancona. Macunaíma pra lá de Brasil. In: ANDRADE, Mário de. Macunaíma, o herói sem nenhum caráter. São Paulo: Círculo do Livro, s.d.

OLIEVENSTEIN, Claude, LAPLANTINE, François. Um olhar francês sobre São Paulo. Tradução de Maria Carneiro da Cunha. São Paulo: Brasiliense, 1993.

PROENÇA, M. Cavalcanti. Roteiro de Macunaíma. 3. ed. Rio de Janeiro: Civilização Brasileira, 1974.

RAMA, Angel. A cidade das letras. São Paulo: Brasiliense, 1985. 